\title{
EVALUATION OF RESULTS OF ARTHROSCOPIC ACL RECONSTRUCTION BY HAMSTRING GRAFT
}

\author{
ALAM MK ${ }^{1}$, SHAMSUZZAMAN M${ }^{2}$, SALAM MI ${ }^{1}$, BHUIYAN MA $^{3}$, HASSAN AZMM $^{3}$, MD.HASAN $^{4}$, \\ SHOMA FK 5
}

\begin{abstract}
:
Bony structure of the knee is inherently unstable. Stability provided by the strong capsule, intra-articular and extra-articular ligaments (ACL, PCL, MCL, LCL) and surrounding muscles. $A C L$ and $P C L$ provides both antero-psterior and rotator stability ${ }^{1}$.Rupture of the Anterior Cruciate Ligament is the most common sports injury worldwide, which causes significant problem in orthopaedic practice. This study was prospective observational study and carried out in Dhaka Medical College Hospital and other private clinic in Dhaka from July 2009 to December 2011. This study was carried out on 22 ACL deficient knees. 2 patients were dropped from final follow-up. All patients were male. Age range was 18-39.Mode of injury were-sports injury 16(80\%), RTA 3(15\%) and fall from height 1(5\%). All the patients were operated for ACL reconstruction by Hamstring graft. Average follow-up period was 12 months. Outcome was evaluated by IKDC rating system. Majority of the patients 17 (85\%) returned to their normal activities one year after operation. The objective of this study is to find out the outcome of ACL reconstruction by Hamstring graft.
\end{abstract}

Key-words: ACL-Anterior Cruciate Ligament; IKDC-International Knee Documentation Committee

J Dhaka Med Coll. 2012; 21(2) : 148-151.

\section{Introduction:}

Knee is the largest synovial joint in the body. As it is uniaxial joint any rotational components make the intra-articular ligament twisted, which make the ligaments prone to injury.

Knee is the most heavily stressed joint in the human frame.$^{2}$ It is most commonly injured because of its anatomic structure, its exposure to external forces and the functional demands placed on it. Knee ligament injuries are common in athletes and other young people who are prone to twisting injury of the knee due to sports and other physical activities. The menisci and the ligaments of the knee sustain injury in contact sports like football, volleyball, basketball etc. The commonest damaging force is a combined rotation and impact injury to the weight bearing semi-flexed / flexed knee, though at times a direct trauma to flexed knee is responsible ${ }^{3}$.
ACL along with PCL it is responsible for the normal gliding and rolling movements of the knee. ACL controls the forward motion as well as medial and lateral rotation of the tibia on the femur .Rupture of this ligament impairs the stability of the knee resulting in decreased athletic activity and increased risk of meniscal tear and early degenerative joint diseases.

Cruciate ligament injuries occur singly or in combination with damage to other structures. ACL is more commonly affected, solitary curciate ligament injuries result in instability in the sagittal plane I,e, anterior -posterior. But if the curciate injuries associated with damage to collateral or the capsule , then the direction of instability is often oblique. ${ }^{1}$

Lesions of the ACL leads to delinking of this rolling and gliding movements with accompanying damage to menisci and the

1. Dr. Mohammad Khurshed Alam, Dr. Sarwar Ibne Salam, Assistant Professor (c.c.), Department of Orthopaedics, Dhaka Medical College Hospital, Dhaka, Bangladesh.

2. Prof. Md. Shamsuzzaman, Professor (c.c.), Department of Orthopaedics, Sir Salimullah Medical College \& Mitford Hospital, Dhaka

3. Dr. Mashfique Ahmed Bhuiyan, Dr. AZM Mahmudul Hassan, Assistant Registrar, Department of Orthopaedics, Dhaka Medical College Hospital, Dhaka.

4. Dr. Md. Hasan, Resident, Department of Orthopaedics, Dhaka Medical College Hospital, Dhaka.

5. Dr. Farzana Khan Shoma, Assistant Professor, Department of Physical Medicine, BIHS, Dhaka

Correspondence: Dr. Mohammad Khurshed Alam, Assistant Professor, Dept. of Orthopaedics, DMCH, E-mail: khursheddmc@gmail.com 
articular cartilage, leading to accelerated osteoarthritis. Hence the need for surgical stabilization by ACL reconstruction ${ }^{4}$.

ACL injury is the most common ligament injury in the knee joint especially in sportsman, arms personals and following RTA. It is the primary stabilizer against anterior translation of the tibia under the femur and also important factor for rotational and valgus stresses. Greater participation in sporting and recreational activities by general population continues to expose more individual to the risk of ACL rupture. ${ }^{5}$

ACL reconstruction has been advocated to improve knee stability and to reduce the incidences of meniscal injury. The controversy for managing this injury now centres more on the choice of graft selection for reconstruction instead of whether surgery is necessary $6,7,8$.

The graft commonly used are- autologus BPTB graft, Hamstring (Semi-Tendinosus and Gracillis) tendon graft, Quadriceps tendon graft, Artificial /synthetic material.

The Arthroscopic approach has the advantage of smaller skin and capsular incisions, less extensor mechanism trauma, improved viewing of the intercondylar notch for placement of the tunnel and attachment sites, less post -operative pain, fewer adhesions, earlier motion and easier rehabilitation ${ }^{9}$.

Patient may need either only ACL reconstruction or ACL reconstruction along with treatment of meniscal lesion. The selection of grafts depends on the surgeon's preference and the tissue currently available ${ }^{10}$.

Among the autogenous tissues currently available, the most commonly used are central one third patellar tendon (BPTB) and quadrupled hamstrings 7,11 .Less commonly quadriceps tendon grafts. ${ }^{12}$

Each of these grafts has been shown to have sufficient load-to -failure strength and stiffness to replace the cruciate ligaments e.g -native ACL-ultimate strength-2160 (N), Native PCL - 1867 (N),BPTBgraft—2977(N), Quadruple Hamstring graft-4140(N),quadriceps Tendon graft-2353 (N). ${ }^{12}$
Reconstruction of ACL in ACL deficient knee is an well accepted therapy of choice in young adult and sportsman. It provides stability to the knee and prevent further deterioration of the joint. There are numerous methods of ACL reconstruction. Our study was on ACL reconstruction by autogenous Hamstring Tendon graft (Semitendinosus alone or with Gracillis).

\section{Materials and methods:}

This study was carried out in Department of Orthopaedics ,Dhaka medical College Hospital, Dhaka and some other private hospitals in Dhaka, Bangladesh from July 2009 to December 2011. Total 22 patients were treated in this prospective observational study. 2 patients were lost from follow up.

\section{Inclusion criteria:}

After epiphyseal closure, no prior knee surgery, no associated PCL injury and no Osteoarthritis.

All patients were male of active age group. Age range of the patients-18-39 (average28.5years). Mode of injury were-sports injury $16(80 \%)$ which includes sportsman e.g. students, athletes, uniform personals, RTA $3(15 \%)$ and fall from height $1(5 \%)$. Out of 20 , 17 patients with right knee (85\%) and $3(15 \%)$ with left knee. Out of 20, 10(50\%) patients had associated meniscus injury. Time interval between injury and surgery was 3 months to 2years.

All the patients were operated for ACL reconstruction by autogenous Semitendinosus Tendon graft with or without Gracillis Tendon graft using metallic interference screw on the Tibial tunnel and Endo/Xo button on the femoral tunnel. All the patients were assessed pre-operatively and followed up on regular basis with an identical 6 month rehabilitation protocol for all patients. Average follow up period was 12 months . Results of the study were evaluated by using IKDC(International knee documentation committee) rating score. Final evaluation was performed 12 months after surgery. 


\section{Surgical Procedure:}

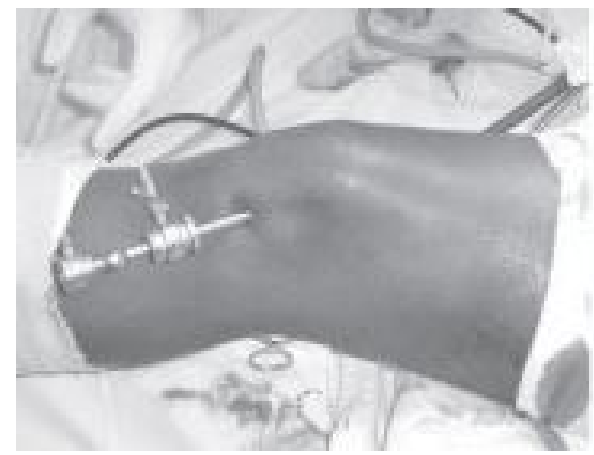

Arthroscopic Evaluation

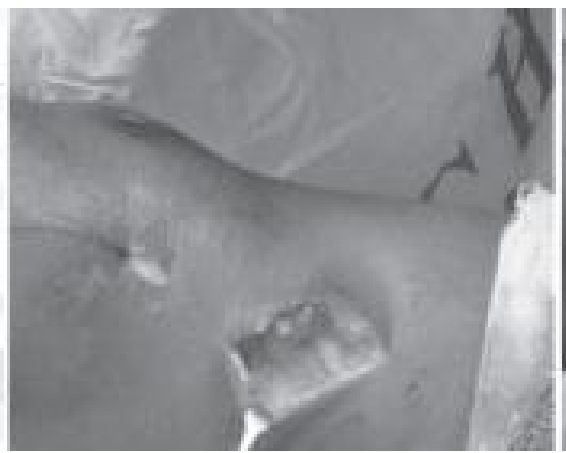

Skin Incision and Graft harvest

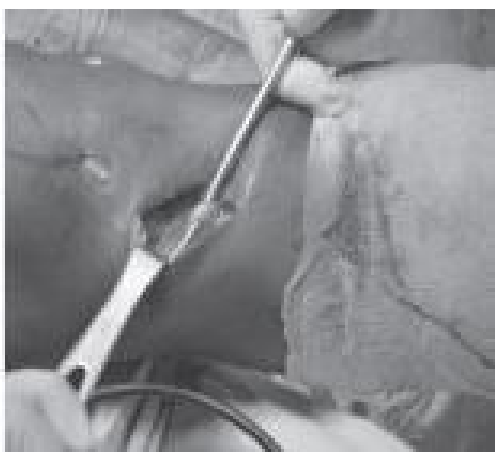

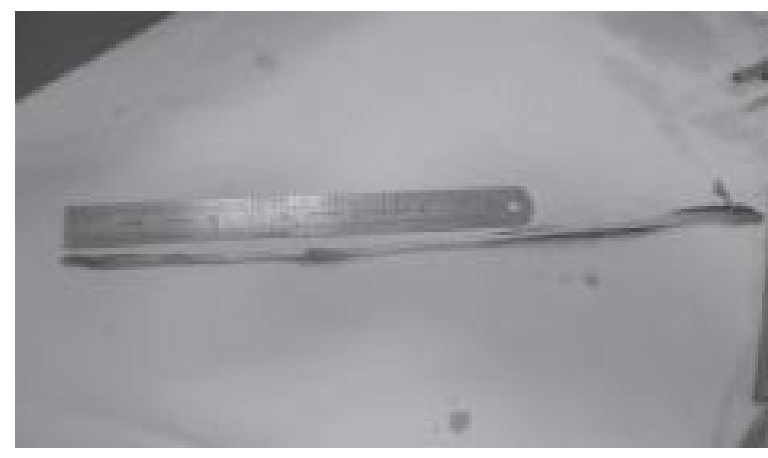

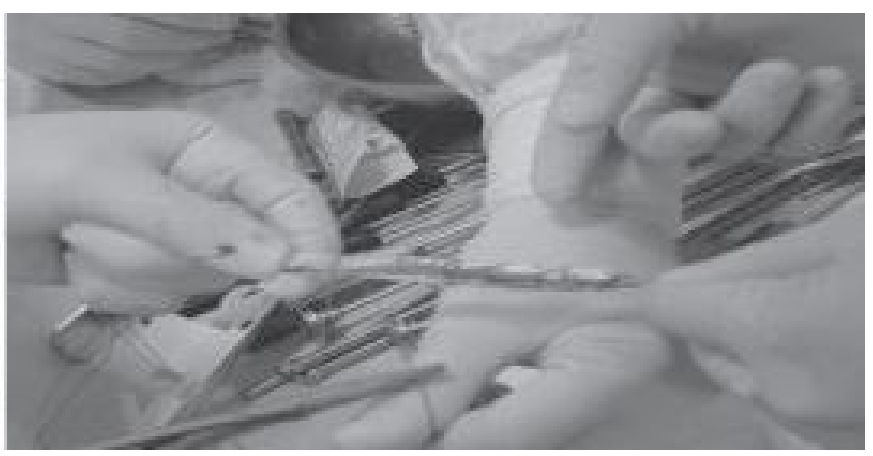

Graft measurement and graft Preparation

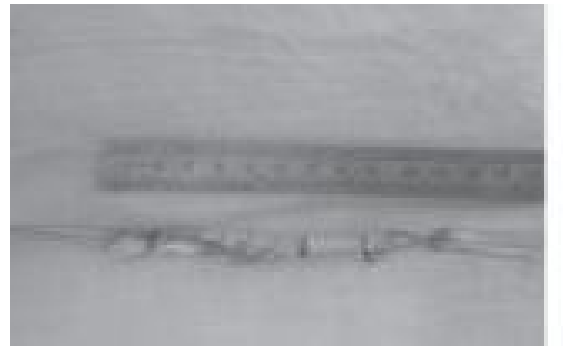

Prepared Quadrepled Hamstring graft

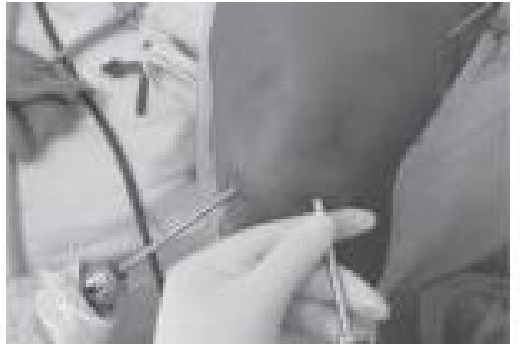

Femoral Tunnel Preparation

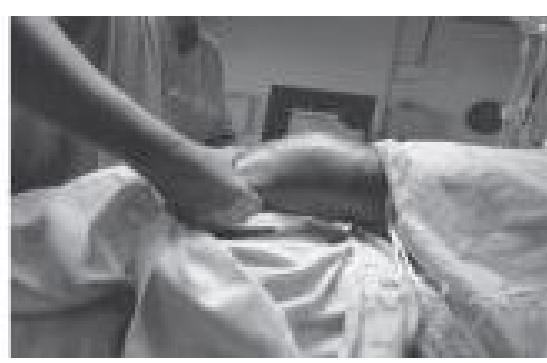

After graft fixation \& wound closure-Lachman test

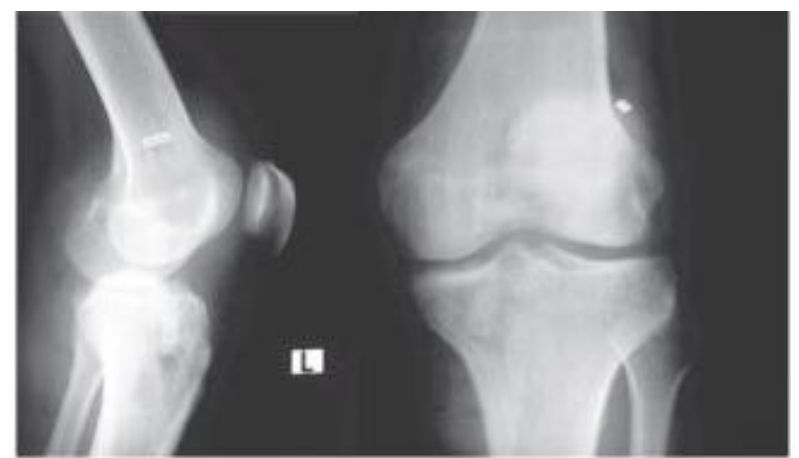

Post-operative Xrays :

\section{Results :}

In this study, out of twenty patients 13 were above 30 years of age, five between 20-30 years and 2 patients below 20 years of age. The minimum age was eighteen and maximum age of the patients were 39 years. Age range was 18-39. Mode of injury were - sports injury $16(80 \%)$, RTA $3(15 \%)$ and fall from height $1(5 \%)$. All the patients under study were male. Average follow-up period was 12 months. Outcome was evaluated by IKDC rating system. 
Majority of the patients $17(85 \%)$ returned to their normal activities one year after operation. Out of 20, $17(85 \%)$ returned to normal activity after one year follow up with full ROM, negative Lachman test and Anterior drawer test. 3 patients had 25-30 degree lack of full flexion. 3 patients had post-operative knee pain and all are associated with meniscus injury. The effect of menisectomy appears to have a negative impact on the outcome of reconstruction. Two patients had superficial wound infection over graft harvesting site which was improved with a course of antibiotics. In one patient there was premature graft harvesting, which was overcome with BPTB graft and screw fixation.

\section{Discussion:}

Arthroscopic techniques have been advanced and refined to assist in the reconstruction of the ACL and PCL. The arthroscopically aided approach has the advantages of smaller skin incision and capsular incisions, less extensor mechanism trauma, improved viewing of the intercondylar notch for placement of the tunnel and attachment sites, less postoperative pain, fewer adhesions, earlier motion and easier rehabilitation. ${ }^{12}$

ACL reconstruction, substituting a free tendon graft for the torn ligament is a common surgical procedure for the orthopaedic surgeons. ${ }^{13}$ In sports injury there might be ligament injury with or without meniscus injury. Most common are ACL with medial meniscus injury but any ligament or meniscus may injured. Because of associated injury some patient experience instability with some degree of pain. The goal of ACL reconstruction is to restore normal knee stability and prevents further injury to the knee joint. ${ }^{13,14,15}$. The ideal graft is one that restrains strength at least equivalent to that of normal ACL, allows for secure fixation, enables unrestricted rehabilitation and has minimum graft donor site morbidity. Now a day Quadripled Semi-T / Hamstring graft is the graft of choice for ACL reconstruction. Historically patellar tendon was the most popular autogenous graft for ACL reconstruction ${ }^{13,14,15}$. Complications like patellar fracture, patellar tendon rupture, patello-femoral pain ,patellar tendonitis, quadriceps weakness and flexion contracture are common ${ }^{31,14}$. Anterior knee pain in study with BPTB graft is $17 \%$ to 56 $\%$ 13.14. But with hamstring graft the above mentioned complications absent
In our study success rate of ACL reconstruction is $85 \%$ which is comparable to other study. In Insall and Norman study, success rate of ACL reconstruction is $75 \%$ to $90 \%$.

\section{Conclusion:}

ACL reconstruction with Quadripled Semi$\mathrm{T}$ (Hamstring) graft/ Tripled Hamstring graft is an excellent reconstruction procedure for most patients. There is no donor site morbidity. But associated meniscus injury correlated with poor outcome. However a long term study and follow-up is needed to demonstrate a significantly good long-term outcome.

\section{References:}

1. Solomon L, Warwick D, Nayagam S. Injuries of the knee and leg ;Apley's System of orthopaedics and Fractures, $8^{\text {th }}$ Edition.2001; p705-706

2. Hutson JC, Acute Knee Injuries in Athletes, Clin. Orthop.1998; 23; 114

3. Brantigan OC. The Mechanics of Ligament and Meniscus of Knee joint ,JBJS 1994;23;44

4. Kannaus P.\& Jarvinen M. Conservatively Treated tear of the Anterior Cruciate Ligament; Long term results ;JBJS .1987; vol 6A,p 1002-1012

5. Inasll JN, Scott WN: Surgery of the Knee.pp-681-690

6. S Cruch, Reconstruction of Anterior Cruciate ligament, JBJS ,2005;87B; 1639.

7. Simonian PT, Levine RE, Wright TM. Response of Hamstring and Patellar tendon graft for Anterior Cruciate Ligament Reconstruction during cyclic tensile loading. Am. J. Knee Sur.2000;13;8

8. Jomha NM, Pinczewski LA, Clingelefer A, Otto DD : Arthroscopic reconstruction of the Anterior Cruciate ligament with Patellar tendon autograft and interference screw fixation. The result at seven years. JBJS ,1999;81;775.

9. Cassels AW,The place of Arthroscopy in diagnosis and treatment of internal derangement of Knee joint; Orthop. Clin. North Am.1980; 151;135.

10. Sick TD, Knee injuries. In: Crenshaw AH. Campbell's Operative Orthopaedics, $10^{\text {th }}$ edn. St. Louis, Missouri,Mosby.2002; pp-510, 767 74;1513;1541;1769-72;1802.

11. Steiner ME, Hoker AT, Brown $\mathrm{CH}$, et al: Anterior Cruciate Ligament graft fixation :Comparison of hamstring and patellar tendon graft. Am J Sport med. 1994;22:240.

12. Canale.ST, Beaty JH, Arthroscopy of the Lower extremity.Campbell's Operative Orthopaedics. $11^{\text {th }}$ Edition, Vol-3, p-2856-2857

13. Insall JN, Scott WN: Surgery of the Knee. pp 681-690.

14. Aglietti P, Buzzi R, D’Andria S,et al : Arthroscopic Anterior Cruciate Ligament Reconstruction with Patellar tendon. Arthroscopy 8: 510,1992

15. Brown C, Steiner M, Carson E : The use of Hamstring tendon for ACL reconstruction : Technique and Results. Clin. Sports Med 12: 723, 1993. 